\title{
ELEVAÇÃO DE VOGAIS MÉDIAS PRETÔNICAS: REGISTROS HISTÓRICOS EM JORNAIS DO SÉCULO XIX
}

\section{PRETONIC VOWELS ELEVATION: HISTORICAL RECORDS IN NEWSPAPERS FROM THE 19TH CENTURY}

\author{
Roberto Francisco Nasi \\ Universidade Federal do Rio Grande do Sul, Porto Alegre, RS, Brasil
}

\begin{abstract}
Resumo: Além da fala, o registro escrito também pode servir como fonte para o estudo de fenômenos de variação e mudança linguística. A grafia de textos produzidos há mais de um século pode atestar a história de uma língua, conforme Bisol (1981). Diante dessa perspectiva, este trabalho propõe a exposição de possíveis variáveis fonológicas, identificadas em análise anterior (NASI, 2012), por meio do registro de certas formas interpretadas como traços da oralidade que podem representar certas variantes existentes nos dias atuais. $\mathrm{O}$ exame que se propõe, neste estudo, segue a proposta de Lass (2000) acerca da investigação de mudança linguística em registros escritos. Utilizam-se, como amostra e corpus, jornais produzidos no Rio Grande do Sul, no século XIX. Com base em registros escritos, pretendemos confirmar a relação passado/presente existente entre dois estados de língua e a existência de certos fenômenos fonológicos na história.

Palavras-Chave: Registro Escrito; Variação Fonológica; Linguística Histórica.
\end{abstract}

Abstract: Besides spoken language, the written record may be considered a source for linguistic variation and change studies. Texts written one century ago can attest the history of a language according to Bisol (1981). Based on this belief, this paper proposes the identification of possible phonological variables through some written records interpreted as oral aspects which may express certain variants currently used by speakers. It was made in a previously (NASI, 2012). The examination in this paper follows the investigation of linguistic change in written records by Lass (2000). By using written records found in newspapers published in the 19th century in Rio Grande do Sul, we intend to certify the past/present relation between two language states and the existence of certain phonological phenomena in history.

Keywords: written record, variables, phonological variation, historical linguistics.

\section{Introdução}

O fenômeno da elevação vocálica, sendo fonologicamente típico da Língua Portuguesa e também uma forma caracterizadora de falares regionais, é presente na variedade brasileira atual, conforme atesta o trabalho de Callou e Moraes (2002). Estudos que demonstram o fenômeno da variedade regional gaúcha também foram feitos, como o de Bisol (1981), Battisti (1993), Schwindt (1995, 2002), Casagrande (2003), Klunck (2007) e Silva (2012). Esses estudos, além de afirmarem o comportamento variável da vogal pretônica como um processo estável em nossa língua, trazem ocorrências obtidas através de minuciosas análises da fala contida em bancos de dados como, por exemplo, os dos projetos VARSUL e NURC. Os dados de fala, isto é, as ocorrências, são tomadas como evidências da existência da elevação vocálica pretônica na 
Língua Portuguesa. Embora essa constatação seja óbvia, quando tratamos de um estado de língua falada atualmente, ela se torna relativamente obscura quando o recorte delimita um estado de língua longínquo no tempo.

Tratar de um estado de língua que não corresponde ao atual ou próximo implica uma série de questões relevantes, principalmente quando não há registros sonoros disponíveis para análise do tempo considerado. Esses questionamentos referem-se à natureza do dado fonológico na escrita, se esse pode realmente ser considerado um reflexo da fala, e, por consequência, uma evidência de um fenômeno fonológico a ser analisado. Infere-se que ocorrências que são hoje atestadas em uma língua fazem parte de seu comportamento evolutivo. Assim, acredita-se ser possível verificar traços de um comportamento específico presente na língua também em seu estado passado. Dessa maneira, os dados possibilitam formar empiricamente a história de uma língua.

Nosso trabalho tem a intenção primordial de, ao trazer os dados de Bisol (1981) e os resultados coletados em Nasi (2012), contribuir para a história da Língua Portuguesa brasileira, mais especificamente, do comportamento variável da vogal pretônica na variedade sul-rio-grandense do português brasileiro. Os dados analisados sugerem indícios de que a variação existente nas vogais pretônicas, conhecida nos dias atuais, já acontecia anteriormente na Língua Portuguesa. Esses dados foram obtidos em corpora formados por jornais escritos em português no século XIX.

Iniciaremos nosso trabalho fazendo breves considerações acerca da elevação das vogais pretônicas. Após, traremos os dados de Bisol $(1981,1983)$ que sugerem a estabilidade da elevação em estados de línguas bastante longínquos no tempo, incluindo a língua latina, antecessora do português. Posteriormente, explicitaremos o corpus formado por jornais gaúchos produzidos durante o século XIX, consultados no Arquivo Histórico Moysés Vellinho, em Porto Alegre, no ano de 2012. Explicaremos a metodologia utilizada para coleta de dados (LASS, 2000) e, em seguida, apresentaremos nossos dados analisados e realizaremos as considerações finais com intenções futuras da pesquisa.

\section{Elevação da pretônica: Bisol (1981)}

As vogais médias altas /e, o/, quando em posição átona, podem ser alçadas para uma posição alta no quadro articulatório do português brasileiro. Essas vogais em posições pretônicas e postônicas podem ser variavelmente realizadas como [e] ou [i] ou como [o] e [u]. Assim, palavras como, por exemplo, boneca, mato, coruja e meninice, podem ser pronunciadas com a vogal média átona na forma [i] e [u], ou seja, buneca, matu, curuja e mininici. 
Este fenômeno de alçamento de altura no quadro articulatório das vogais médias /e, o/, em posição átona, pode ser caracterizado por três processos fonológicos, conforme Bisol (2010): harmonia vocálica, neutralização e alçamento sem motivação aparente.

O processo de harmonia vocálica tem como gatilho as vogais altas /i/ ou $/ \mathrm{u} /$, adjacentes às vogais médias /e/ e /o/ dentro da palavra. A vogal em posição pretônica assimila os traços de altura característicos da vogal gatilho. A neutralização se caracteriza pela perda de um traço distintivo quando dois fonemas reduzem-se a uma unidade fonológica. Já o processo de redução vocálica está mais fortemente relacionado aos casos categóricos da realização da vogal alta em posição pretônica, como a posição inicial de palavra associada ao travamento silábico por /s/, ou formando sílaba nasalizada. Acreditamos que a produção do fenômeno de elevação vocálica atualmente se dá graças aos vestígios trazidos na língua do processo já existente.

Conforme Bisol,

[...] a instabilidade da vogal pretônica que caracterizou o velho português deixou vestígios no português brasileiro, cujos falantes substituem variavelmente /e, o/ pelas respectivas vogais /i, u/, sob o efeito de certos condicionadores. Ex. coruja $\sim$ curuja, menino $\sim$ minino (BISOL, 1981, p. 29).

Dessa forma, Bisol (1981) realizou, em sua tese de doutorado, uma minuciosa análise por meio de um corpora formado por textos datados do século IV d.C. até o século XVIII. As fontes são as seguintes: Appendix Probi (século IV d.C.), The Latinity of Dates Documents in the Portuguese Territory, de Norman P. Sacks (obra de 1941 que traz ocorrências dos anos 770 a 1120), Orto do Esposo (1381), Tratado de Confisson (1489), Os Lusiadas de Camões (1572), Thesouro da Lingua Portuguesa (1647) e Regras Gerais (1666) de Bento Pereyra e, por fim, Compendio de Orthografia ou Arte de Escrever e Pronunciar com acerto a Lingua Portuguesa (1739) de Madureira Feijó. Nessas obras a coleta é feita através das listas de palavras corretas contrapostas às incorretas. Isso foi feito intuitivamente pela autora para expressar o grau de probabilidade da elevação vocálica motivada por harmonização. Conforme nosso quadro a seguir: 


\begin{tabular}{|c|c|c|c|c|}
\hline Obra & Autor & $\begin{array}{l}\text { Ano- } \\
\text { Século }\end{array}$ & Probabilidade & Exemplos \\
\hline $\begin{array}{l}\text { Appendix } \\
\text { Probi }\end{array}$ & $\begin{array}{c}\text { Professor } \\
\text { africano }\end{array}$ & IV d.C. & $\begin{array}{c}\text { variável } \\
\text { remanescente: } \\
\text { formiga furmiga }\end{array}$ & $\begin{array}{l}\text { Formica non furmica } \\
\text { Festuca non fistuca } \\
\text { Robigo non rubigo }\end{array}$ \\
\hline $\begin{array}{l}\text { The } \\
\text { Latinity of } \\
\text { Dates } \\
\text { Documents } \\
\text { in the } \\
\text { Portuguese } \\
\text { Territory }\end{array}$ & $\begin{array}{l}\text { Norman } \\
\text { Sacks }\end{array}$ & $\begin{array}{c}1941 \text { - traz } \\
\text { ocorrências } \\
\text { dos anos } \\
770 \text { a } 1120\end{array}$ & $\begin{array}{c}\text { variáveis } \\
\text { favorecidas pela } \\
\text { atual escrita: } \\
\text { enfermidade }= \\
\text { infirmidade } \sim \\
\text { infermidade } \\
\text { testemunho = } \\
\text { testemunho test } \\
\text { imunho. Ao } \\
\text { restante, vogal } \\
\text { alta na silaba } \\
\text { seguinte ou pela } \\
\text { presença de velar } \\
\text { ou labial vizinhas } \\
\text { a o. }\end{array}$ & $\begin{array}{l}\text { pigureiro < pecuriarium, } \\
\text { piliteiros }<\text { pellitarios, } \\
\text { vinder }<\text { vendere, } \\
\text { mulinos }<\text { molina, } \\
\text { infirmidade }<\text { infirmitatem, } \\
\text { testimonias }<\text { testimonia }\end{array}$ \\
\hline $\begin{array}{l}\text { Orto do } \\
\text { Esposo }\end{array}$ & $\begin{array}{l}\text { Texto } \\
\text { religioso }\end{array}$ & 1381 & $\begin{array}{c}77 \text { formas, } 68 \\
\text { prováveis }=88 \%\end{array}$ & $\begin{array}{l}\text { acustumar acostumar, } \\
\text { celicio } \sim \text { cilicio, } \\
\text { cobertura } \sim \text { cubertura, } \\
\text { cobrir cubrir, } \\
\text { concebimento } \sim \text { concibiment } \\
\text { o, medida midida, } \\
\text { menino minino }\end{array}$ \\
\hline $\begin{array}{l}\text { Tratado de } \\
\text { Confisson }\end{array}$ & & 1489 & $\begin{array}{c}45 \text { formas, } 38 \\
\text { prováveis }=84 \%\end{array}$ & $\begin{array}{l}\text { avorrecivel avorricivel, } \\
\text { cerimonias } \sim \text { cirimonias, } \\
\text { costume } \sim \text { custume, } \\
\text { conbicimento, desconbicido, } \\
\text { ducura, encubrido, } \\
\text { espicial, } \\
\text { formigasses furmigasti }\end{array}$ \\
\hline $\begin{array}{c}\text { Os } \\
\text { Lusíadas }\end{array}$ & Camões & 1572 & $\begin{array}{c}30 \text { formas } \\
\text { prováveis }= \\
100 \%\end{array}$ & $\begin{array}{l}\text { devido } \sim \text { divido, engulindo, } \\
\text { encuberto, gingiva, minino, } \\
\text { mintirosa, perigo } \sim \text { pirigo, } \\
\text { surrindo }\end{array}$ \\
\hline $\begin{array}{c}\text { Thesouro } \\
\text { da Língua } \\
\text { Portuguesa } \\
\text { Regras } \\
\text { Gerais }\end{array}$ & $\begin{array}{l}\text { Bento } \\
\text { Pereyra }\end{array}$ & $\begin{array}{l}1647 \\
1666\end{array}$ & $\begin{array}{c}44 \text { formas, } 35 \\
\text { prováveis }=80 \%\end{array}$ & $\begin{array}{l}\text { cobica } \sim \text { cubica, } \\
\text { coruja curuja, } \\
\text { devido } \sim \text { divido, } \\
\text { focinho fucinbo }\end{array}$ \\
\hline
\end{tabular}




\begin{tabular}{|c|c|c|c|c|}
\hline $\begin{array}{c}\text { Compendio } \\
\text { de } \\
\text { Orthografia } \\
\text { ou Arte de } \\
\text { Escrevere } \\
\text { Pronunciar } \\
\text { com acerto } \\
\text { a Lingua } \\
\text { Portuguesa }\end{array}$ & $\begin{array}{l}\text { Madureira } \\
\text { Feijó }\end{array}$ & 1739 & $\begin{array}{c}158 \text { formas, } 117 \\
\text { prováveis }=74 \%\end{array}$ & $\begin{array}{l}\text { alecrim } \sim \text { alicrim, } \\
\text { algodão algudão, } \\
\text { appetite } \sim \text { appitite, } \\
\text { arrepiar arripiar, } \\
\text { assegurar assigurar, } \\
\text { moribundo muribundo, } \\
\text { partelleira } \sim \text { partilleira, } \\
\text { vestigio } \sim \text { vistigio }\end{array}$ \\
\hline
\end{tabular}

Todos os textos apresentaram inúmeras palavras com alternância na escrita de e $\sim$ i e o $\sim$ u pretônicos. Nas ocorrências coletadas no Appendix Probi, por exemplo, uma em especial permanece até hoje como variável fonológica estável no português brasileiro: formiga, grafada com o, é muitas vezes pronunciada como furmiga. A contra-indicação da pronúncia furmica na língua latina atesta um possível comportamento variável da vogal pretônica o ao ser elevada a u já no passado; neste caso, configurando elevação motivada pela harmonização vocálica devido à presença de vogal alta (i) na sílaba seguinte.

Nos outros textos, a ocorrência do fenômeno é afirmada como alta nos tempos antigos da Língua Portuguesa, com probabilidade variável de $74 \%$ a $100 \%$ de registros escritos que poderiam ser reconhecidos na pronúncia atual como casos de elevação de vogais pretônicas. Conforme Bisol (1981, p. 236), "do século XVI ao XVII, as listas de palavras 'erradas e emendadas', onde ainda figuram contraditórias trocas de vogais como erros ortográficos, trazemnos vestígios da pronúncia de então”.

Curiosamente, há carência de descrições sobre possível variação fonológica durante o século XIX. Relevante ainda, a este período do tempo, é a atribuição da transição da língua lusitana para a definição de uma variedade genuinamente brasileira, já no século XX. Segundo Melo (1946, p. 11), a preocupação em se definir uma Língua Portuguesa brasileira se iniciou com a proclamação da Independência, embora depois de 1930 tenham surgidos muitos trabalhos que tiveram por objeto a realidade linguística brasileira. Conforme o autor:

Foi exatamente num momento de intensificação do sentimento nacional, naquele ambiente de exaltação patriótica que preparou, viu e sobreviveu à proclamação da Independência, que surgiu a preocupação da língua própria. Não tão nítida como agora, é bem verdade. Porém, houve ainda em 1826, quem salientasse que a língua do Brasil já não era a mesma, absolutamente a mesma que a de Portugal (MELO, 1946, p. 11).

Assim, ao provermos dados possivelmente fonológicos desse tempo, colaboramos para descrições futuras desse estado da Língua Portuguesa. Para isso, uma seleção de textos escritos para composição de corpus se fez necessária. 
Devido à dificuldade de interpretação das fontes manuscritas inicialmente encontradas, escolhemos uma fonte impressa disponível para a formação de um corpus consistente e que refletisse, de certa forma, a língua do povo gaúcho no século XIX: o jornal, um suporte de escrita que acreditamos expressar um comportamento linguístico. A seguir, exporemos os títulos que foram analisados em nossa pesquisa.

\section{Jornais gaúchos do século XIX}

Os dados trazidos por Nasi (2012) foram retirados dos seguintes jornais produzidos no Rio Grande do Sul durante o século XIX: O Mensageiro (1835), O Povo (1838), O Americano (1842), Estrella do Sul (1843), O Jornal do Commercio (1867), A Voz do Escravo (1881), A Federação (1892) e A Gazetinha (1891 a 1898). A coleta inicial teve como intenção encontrar dados que ilustrassem a variação presente na escrita.

O quadro abaixo nos traz a relação dos títulos e a quantidade de exemplares analisados de cada um:

\begin{tabular}{|l|l|l|}
\hline \multicolumn{1}{|c|}{ Título } & \multicolumn{1}{|c|}{$\begin{array}{c}\text { Ano de } \\
\text { publicação }\end{array}$} & \multicolumn{1}{|c|}{$\begin{array}{c}\mathbf{N}^{\mathbf{o}} \text { de } \\
\text { exemplares }\end{array}$} \\
\hline O Mensageiro & $(1835-1836)$ & 18 jornais \\
O Povo & $(1838-1840)$ & 17 jornais \\
O Americano & $(1842-1843)$ & 13 jornais \\
Estrella do Sul & $(1843)$ & 3 jornais \\
Jornal & $(1867-1868)$ & 34 jornais \\
Commercio & $(1881)$ & 3 jornais \\
A Vozdo Escravo & $(1891-1898)$ & 170 jornais \\
A Gazetinha & $(1892-1900)$ & 17 jornais \\
A Federação & & \\
\hline
\end{tabular}

Alguns desses jornais, principalmente $A$ Gazetinha, utilizavam uma linguagem de forte teor sensacionalista, sendo escritos pelo povo e para $\mathrm{o}$ povo. Os proprietários dos jornais eram, muitas vezes, também redatores dos periódicos. Esses redatores ocupavam outras funções além da imprensa local e, como homens do povo, utilizavam a língua vernácula daquele tempo e daquele território. Conforme o trecho retirado da primeira página de $A$ Gazetinha, na edição de 11 de julho de 1898: "Os escriptores da 'Gazetinha', sem excepção de um único, são todos elles homens pobres, alguns paupérrimo [...]. Alguns 
dentre elles são simples operarios, que furtam diariamente algumas horas ao repouso, trocando a ferramenta pela penna [...]".

Dessa forma, acreditamos que a variação escrita contida nos jornais possa nos munir com dados fonologicamente relevantes para provermos dados diacrônicos de fenômenos fonológicos. Porém, a coleta desse tipo de dado em fonte escrita requer determinados cuidados que trataremos a seguir em nossa metodologia.

\section{Metodologia}

Nossa coleta toma como ponto de partida a noção de variável linguística nos termos de Weinreich, Labov e Herzog, que a definem como "meios alternativos de dizer a mesma coisa" (WEINREICH et al., 2009, p. 97). Consideramos variáveis linguísticas fonológicas identificadas na língua falada do português brasileiro, ou seja, casos alternativos de realização de /o/ pretônico, por exemplo, registrados graficamente com a letra u como uma variante de variável fonológica, assim como os registros escritos com i, representando possivelmente alçamento de vogal média /e/.

Desse modo, formas variantes obtidas por meio de certa representação escrita foram tratadas neste trabalho como parte de variáveis. Conforme Labov (1982, p. 20), utilizar-se da escrita para refletir sobre a variação inerente à mudança linguística é "a arte de fazer o melhor uso dos maus dados". Para fazermos a melhor utilização de dados escritos, recorremos ao "Princípio de Remoção de Filtro" (SCHNEIDER, 2002, p. 68), para o qual um registro escrito de um evento de fala representa um filtro entre as palavras faladas e o estudioso que as analisa. O papel do linguista é remover esse filtro, reconstruir a natureza do processo do registro de todas as maneiras possíveis e avaliar o que é relevante no impacto provável entre o evento de fala e a ocorrência escrita, isto é, reconstruir o evento de fala o mais precisamente possível. Embora acreditemos que a escrita corresponda à fonologia de uma língua, podem ocorrer, além de violações da relação grafema-fonema no sistema alfabético, equívocos de interpretação das formas escritas, já que, ainda de acordo com Schneider (2002, p. 68), o "filtro pode não estar sendo removido corretamente".

Para a devida remoção, buscamos auxílio no tratamento de formas escritas trazido na taxonomia de Lass (2000), apresentada a seguir.

Taxonomia para desvios de escrita, segundo Lass (2000, p. 62):

a) Lixo/Garbage - são aquelas formas que não são passíveis de interpretação, não podendo ser outra coisa a não ser lapsus calami. São os erros ortográficos visíveis a olho nu, por exemplo, a troca de grafemas, como a escrita fazenad em vez de fazenda. 


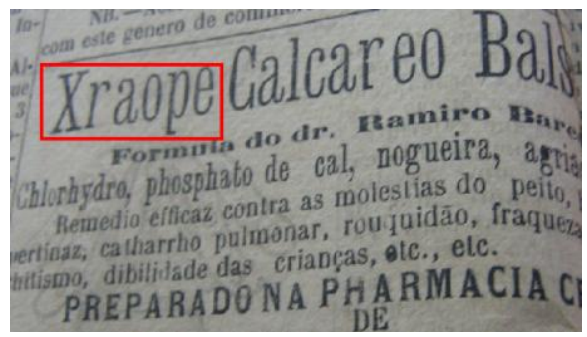

Figura 01 - exemplo de lixo gráfico

Fonte: $A$ Gazetinha

b) Variação puramente gráfica/Purely graphic variation - são as formas de registro resultantes de uma tradição escrita, por exemplo, ocorrências que já fossem prescritas por regras existentes na grafia da época ou por traços etimológicos. No caso do português brasileiro, temos a variação decorrente da duplicação de grafemas, como attendidos em vez de atendidos, e a utilização de ph em pharmacia, como exemplo de palavras pertencentes à tradição escrita da época de um estágio de língua passado. O plural terminado em -es também era tradição gramatical da época.

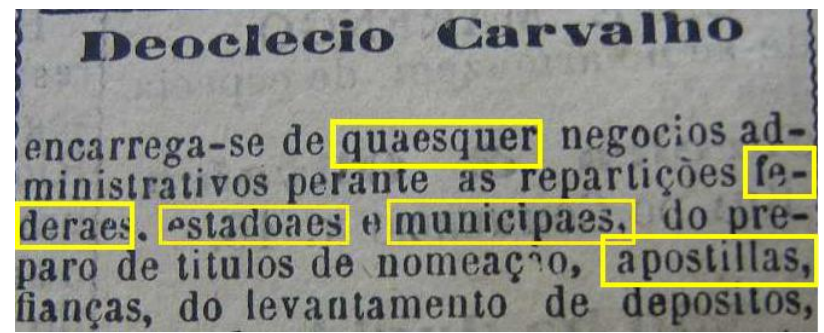

Figura 02 - exemplo de variação gráfica

Fonte: $A$ Gazetinha

c) Grafia significativamente fonológica/Phonologically significant spellings - é a grafia que pode expressar processos fonológicos, tornando-se a informação relevante para nossa pesquisa. Uma escrita próxima à fala como conhecemos hoje. 


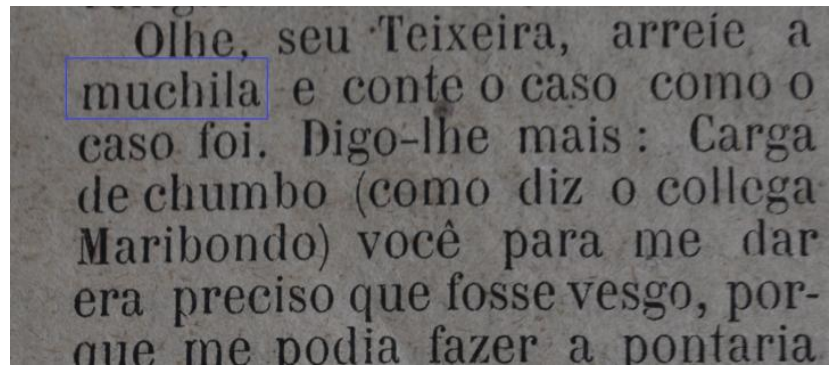

Figura 03 - exemplo de dado significativamente fonológico Fonte: A Gazetinha

Realizando a diferenciação tratada acima, realizamos a coleta para análise, o que explicitamos a seguir.

\section{Registros históricos}

A análise dos jornais teve como principal objetivo a coleta de registros escritos que pudessem expressar a elevação das vogais pretônicas como a conhecemos hoje. A forma de elevação atual é própria do estado presente da Língua Portuguesa, o que nos fornece a base para a reconhecermos, na escrita, os dados encontrados que acreditamos possuírem relevância fonológica. A identificação dos registros escritos que exibiremos a seguir como possíveis formas de expressão de vogais médias elevadas na grafia transforma os dados em registros históricos da alternância entre vogais médias e altas em contextos fonológicos por nós já conhecidos.

Nos 275 jornais lidos, constatamos 154 ocorrências de registros escritos, os quais acreditamos possuírem valor fonológico. Dentre as ocorrências, 54 formas escritas podem expressar elevação vocálica pretônica, já que esse fenômeno apresenta na fala um i e u como realização do grafema e e o da ortografia. Expomos os dados a seguir, destacando a vogal alta $\mathbf{i}$ ou $\mathbf{u}$ grafada como alternante nas palavras nas quais esperaríamos (pela grafia atual) a grafia de uma vogal média e ou o.

1. compitentemente, $O$ Povo, 26 de setembro de 1838, p. 2;

2. cuberto, $O$ Mensageiro, $1^{\circ}$ de dezembro de 1835 , p. 1 ;

3. disgraçados, $O$ Povo, 26 de setembro de 1838, p. 1;

4. dispertado, A Gazetinha, 20 de março de 1892, p. 1;

5. dispertam, $A$ Gazetinha, 15 de novembro de 1891, p. 1;

6. dispertavas, $A$ Gazetinha, 17 de janeiro de 1892, p. 3;

7. dispotismo, $A$ Voz do Escravo, 15 de fevereiro de 1881, p. 1

8. disprezo, O Povo, 26 de setembro de 1838, p. 3; 
9. incarna, $A$ Gazetinha, 10 de setembro de 1898, p. 1;

10. incontinenti, $A$ Gazetinha, 3 de abril de 1892, p. 1;

11. intretenimento, $A$ Gazetinha, 24 de abril de 1892, p. 4;

12. marcineiro, $A$ Gazetinha, 5 de maio de 1898 , p. 3;

13. ocurrencia, $O$ Americano, 24 de setembro de 1842, p. 3;

14. sinão, $A$ Federação, 4 de abril de 1892, p.3 ;

15. sinão, $A$ Gazetinha, 20 de dezembro de 1891, p. 4;

16. siquer, $A$ Gazetinha, 28 de fevereiro de 1892, p. 1;

Entre as 54 ocorrências escritas com variação ortográfica das vogais, observamos que 16 destas expressam elevação variável das vogais. As 38 ocorrências a seguir revelaram a escrita de palavras que acreditamos manifestarem elevação vocálica por harmonização, isto é, na qual uma vogal alta na sílaba seguinte atua como gatilho da elevação de uma vogal média pretônica. As ocorrências podem ser vistas a seguir:

1. anticipadamente, Estrella do Sul, 15 de março de 1843, p. 3;

2. arripie, $A$ Gazetinha, 28 de fevereiro de 1892, p. 1;

3. assimilham, $A$ Gazetinha, 15 de novembro de 1891, p. 1;

4. benificio, $A$ Gazetinha, 12 de maio de 1898, p. 2;

5. benificente, $O$ Americano, 19 de outubro de 1842, p. 3;

6. confissionario, A Gazetinha, 22 de agosto de 1898, p. 1;

7. cusinha, O Jornal do Commercio, 5 de novembro de 1867, p. 4;

8. cusinhar, O Jornal do Commercio, 7 de novembro de 1867, p. 4 ;

9. cusinheiro, O Jornal do Commercio, 7 de novembro de 1867, p. 6 ;

10. dicididamente, $A$ Gazetinha, 27 de dezembro de 1891, p. 3;

11. dicidido, Estrella do Sul, 15 de março de 1843, p. 1;

12. dimittidos, $O$ Mensageiro, $1^{\circ}$ de dezembro de 1835, p. 2;

13. disfrute, $A$ Gaz̧etinha, 20 de março de 1892, p. 3;

14. discripção (descrição), O Mensageiro, 8 de janeiro de 1836, p. 4;

15. difinitivas, $A$ Gazetinha, 9 de maio de 1898, p. 2;

16. dimittidos, $O$ Povo, 24 de outubro de 1838, p. 66;

17. discidisse, $A$ Gazetinha, 9 de maio de 1898, p. 2;

18. distilada, $A$ Federação, $1^{\circ}$ de janeiro de 1892 , p. 4;

19. distino, $O$ Povo, 24 de outubro de 1838, p. 65;

20. enguli, $A$ Gazetinha, 20 de março de 1892, p. 2;

21. engulideiras, $A$ Gazetinha, 31 de janeiro de 1892, p. 3;

22. similhantes, $A$ Gazetinha, 15 de novembro de 1891, p. 1;

23. indiabrado, $A$ Gazetinha, 27 de dezembro de 1891, p. 2; 
24. indireitarem, $A$ Gazetinha, $1^{\circ}$ de setembro de 1898, p. 1;

25. individamente, $O$ Povo, 6 de março de 1839, p.189;

26. intrincheirados, $O$ Americano, 29 de outubro de 1842, p. 2;

27. intrincheiramento, $A$ Gazetinha, 12 de maio de 1898, p. 2;

28. muchila, $A$ Gazetinha, 22 de novembro de 1891, p. 4;

29. muribundo, $A$ Voz do Escravo, 3 de abril de 1881, p. 1;

30. persiguiáo, $O$ Americano, 8 de outubro de 1842, p. 4;

31. persiguiçáo, $O$ Americano, $1^{\circ}$ de outubro de 1842 , p. 3 ;

32. persiguindo, $O$ Mensageiro, 10 de novembro de 1835, p. 3;

33. pussuidor, $A$ Gazetinha, 12 de dezembro de 1897, p. 2;

34. similhança, $A$ Gazetinha, 6 de setembro de 1898, p. 1;

35. similhante, $O$ Povo, 24 de outubro de 1838, p. 66;

36. sudueste, $A$ Gažetinha, 13 de março de 1892, p. 4;

37. urgias (orgias), A Gazetinha, 4 de outubro de 1898, p. 1;

38. Viríssimo, A Gazetinha, 20 de março de 1892, p. 2.

Assim como nos dados trazidos por Bisol (1981), a variação na grafia das vogais pretônicas é visível. Essa variação não acompanha somente os vocábulos acima listados, mas toda a gramática do português utilizado na época em que uma gramática normativa uniforme da Língua Portuguesa brasileira era ausente. O que hoje se considera erro ortográfico, foi, no século XIX, um comportamento gráfico variável. Conforme a autora (BISOL, 1981, p.237) "estamos assumindo que tais erros ortográficos são reflexos de uma peculiaridade da pronúncia da época". Faremos, a seguir, nossas considerações finais e apresentaremos futuras intenções de pesquisa.

\section{Conclusão}

O longo trabalho envolvido no processo e a pouca quantidade de dados torna esta pesquisa de caráter qualitativo. Esperamos tornar o estudo mais quantitativo, para que a probabilidade do fenômeno da elevação possa ser minimamente mensurada. O trabalho é moroso e demanda tempo. O olhar atento do pesquisador ao diferenciar o lixo e a variação gráfica de dado possivelmente fonológico é fundamental para a coleta deste tipo de registro.

Neste estudo, pudemos trazer o que consideramos indícios do passado de um fenômeno fonológico hoje conhecido, a elevação das vogais médias pretônicas, por meio de vestígios da fonologia do português brasileiro no século XIX. No entanto, o jornal, como suporte escrito, nos trouxe poucos dados confiáveis por estar sujeito à revisão e, ainda, trazer uma escrita formalizada, embora variável. Pretendemos estender nossa análise a outros tipos textuais também produzidos no século XIX: cartas, memorandos e outros documentos. 


\section{REFERÊNCIAS}

BISOL, L. Harmonia vocálica: uma regra variável. Tese (Doutorado em Letras). Universidade Federal do Rio de Janeiro. Rio de Janeiro - RJ, 1981.

- A Simetria no Sistema Vocálico do português Brasileiro. Revista de Estudos Linguísticos da Universidade do Porto, v. 5 , p. 41-52, 2010. BATTISTI, E. Elevação das Vogais Médias Pretônicas em Sílaba Inicial de Vocábulo na Fala Gaúcha. 125 p. Dissertação (Mestrado em Letras). Universidade Federal do Rio Grande do Sul. Porto Alegre - RS, 1993.

CALLOU, D.; LEITE, Y.; MORAES, J. A elevação das vogais pretônicas no Português do Brasil: processo(s) de variação estável. Letras de Hoje, n. 127. Porto Alegre: EDIPUCRS, p. 9-24, 2002.

CASAGRANDE, G. P. B. Harmonização Vocálica: Análise Variacionista em Tempo Real. Dissertação (Mestrado em Letras). Pontifícia Universidade Católica do Rio Grande do Sul. Porto Alegre - RS, 2003.

KLUNCK, P. Alçamento da Vogais Médias Pretônicas sem Motivação Aparente. Dissertação (Mestrado em Letras). Pontifícia Universidade Católica do Rio Grande do Sul. Porto Alegre - RS, 2007.

LABOV, W. Building on empirical foundations. In: W. Lehmann; Y. Malkiel. Perspectives in Historical Linguistics. Amsterdam: John Benjamins, 1982, p. 17-82.

LASS, R. Historical Linguistics and Language Change. Cambridge, 2000. MELO. G. C. A Língua do Brasil. Rio de Janeiro: AGIR, 1946.

NASI, R. F. Variáveis Fonológicas em Jornais Gaúchos do Século XIX. Dissertação (Mestrado em Letras). Universidade Federal do Rio Grande do Sul. Porto Alegre - RS, 2012.

SCHWINDT, L. C. A harmonia vocálica em dialetos do sul do país: uma análise variacionista. Dissertação (Mestrado em Letras). Pontifícia Universidade Católica do Rio Grande do Sul. Porto Alegre - RS, 1995.

SCHNEIDER, E. W. 2002. Investigating variation and change in written documents. In: CHAMBERS, J. K.; TRUDGILL, P.; SCHILLING-ESTES, N. The Handbook of Language Variation and Change. Oxford, Malden, MA: Blackwell, 2002, p. 67-96.

. A regra variável de harmonização vocálica no RS. In: BISOL, L.; BRESCANCINI, C. Fonologia e Variação, recortes do português brasileiro. Porto Alegre: EDIPUCRS, 2002.

SILVA, M. E. O Alçamento das Vogais Médias Pretônicas na fala de São José do Norte/RS: harmonia vocálica. Dissertação (Mestrado em Letras). Universidade Federal do Rio Grande do Sul. Porto Alegre - RS, 2012.

WEINREICH, U; LABOV, W, HERZOG, M. Fundamentos empíricos para uma mudança linguística. São Paulo: Parábola, 2009. 